\title{
ACC/AHA Ischemic ECG Changes
}

National Cancer Institute

\section{Source}

National Cancer Institute. ACC/AHA Ischemic ECG Changes. NCI Thesaurus. Code

C116138.

An electrocardiographic finding, in the absence of left ventricular hypertrophy (LVH) and left bundle branch block pattern on ECG, of either a) new (or presumed new) ST elevation at the J point in two contiguous leads with the following cut-points: greater than or equal to $0.1 \mathrm{mV}$ in all leads other than leads V2-V3 where the following cut points apply: greater than or equal to $0.2 \mathrm{mV}$ in men age greater than or equal to 40 years, greater than or equal to $0.25 \mathrm{mV}$ in men age greater than 40 years, or greater than or equal to $0.15 \mathrm{mV}$ in women; or b) new (or presumed new) horizontal or down-sloping ST depression greater than or equal to $0.05 \mathrm{mV}$ in two contiguous leads, and/or T wave inversion greater than or equal to $0.1 \mathrm{mV}$ in two contiguous leads with a prominent R wave, or R/S ratio greater than 1. (Thygesen K, Alpert JS, Jaffe AS, et al.: the Writing Group on behalf of the Joint ESC/ACCF/AHA/WHF T ask Force for the Universal Definition of Myocardial Infarction. J Am Coll Cardiol 60(16):1-18, 2012) 